\title{
Using the Loss-Free Resistor concept to design a simple ac- dc HB-LED driver for retrofit lamp applications
}

\author{
Diego G. Lamar, Manuel Arias, Marta M. Hernando and Javier Sebastian \\ Universidad de Oviedo. Grupo de Sistemas Electrónicos de Alimentación (SEA) \\ Edificio Departamental n ${ }^{\circ}$ 3. Campus Universitario de Viesques. 33204 Gijón. SPAIN \\ gonzalezdiego@uniovi.es
}

\begin{abstract}
Currently acknowledged, as a rapidly emerging technology, High-Brightness Light-Emitting Diodes (HB-LEDs) are considered the true alternative to many mature technologies (i.e., incandescent bulbs, compact fluorescent lamps, etc.) due to their high efficiency, low maintenance and durability. It is evident that the HB-LED driver must be durable and efficient to achieve these advantages. Moreover, in the case of replacing incandescent bulbs, the ac-dc HB-LED driver needs to be low cost and to have a high enough Power Factor (PF) to comply with international regulations. This paper presents a new proposal to design a simple low-cost ac-dc HB-LED driver for retrofit bulb lamps. The proposed solution originates from a very simple concept: the use a Switching Mode Power Supply (SMPS) acting as a Loss-Free Resistor (LFR) connected in series with the rectified mains to shape the line input current. For the proposed application, it is obvious that the LFR needs to have a very simple topology to be economical. However, efficiency cannot be ignored. This paper proposes the flyback converter working as a LFR connected in series with the rectified mains, operating in Boundary Conduction Mode (BCM) in order to improve its efficiency. First, a static analysis of the proposed concept will be presented. A distortion analysis of the input current of the proposed ac-dc HBLEDs driver will then be carried out to test compliance with international regulations. Finally, two $12 \mathrm{~W}$ experimental prototypes has been built and tested in order to validate the theoretical results presented in this paper. These results show the proposed ac-dc HB-LED driver to be a low-cost, high efficiency, quasi-sinusoidal input current option for designing retrofit lamps.
\end{abstract}

\section{INTRODUCTION}

In recent years, progress in solid-state lighting technology has brought about a change in traditional solutions in lighting. HighBrightness Light-Emitting Diodes (HB-LEDs) have become very attractive light sources due to their excellent characteristics: high efficiency, longevity and low maintenance [1-2]. In addition, HBLED packages are increasingly more robust, providing higher reliability than traditional light sources (fluorescents lamps, incandescent lamps, etc.). To make the most of the aforementioned advantages of HB-LEDs lamps, it is evident that HB-LED drivers must be both durable and efficient.

This work was supported by the Spanish Ministry of Education and Science under Consolider Project RUE CSD2009-00046 and under Project DPI2010-21110-C02-0, by the University of Oviedo under the Project UNOV13-EMERG-GIJON-12 and by European Regional Development Fund (ERDF) grants.
Given that HB-LEDs are diodes, the default method for driving them is by controlling the dc forward current through the semiconductor device. If the primary energy source is the ac line, then some type of ac-dc converter must be placed between the line and the HB-LEDs [3-6]. Furthermore, it is a well-known fact that the low-frequency harmonic content of the line current must comply with specific regulations (EN 61000-3-2 [7-10] and the ENERGY STAR ${ }^{\circ}$ program [10]). Traditionally, as these regulations establish a very strict harmonic content for lighting (e.g., EN 61000-3-2, Class C), only highly sinusoidal line waveforms are able to comply with the aforementioned regulations. Therefore, the only practical way to comply with these regulations is to use active high Power Factor (PF) converters. These converters are known as Power Factor Correctors (PFCs). However, for power levels lower than $25 \mathrm{~W}$, compliance with the EN 61000-3-2 regulation becomes more relaxed due to the fact that luminaries must comply with this regulation in Class D [7-9]. A highly sinusoidal input current is hence not required in these cases and PFCs, which shape a sinusoidal input current, are therefore not mandatory.

To substitute incandescent bulbs lamps, strings of around 12 $\mathrm{x}$ 1W HB-LEDs need to be connected to the output of an ac-dc driver in order to produce the same luminance flux as that produced by a $60 \mathrm{~W}$ incandescent bulb. An illustrative example could be a 12 HB-LED configuration placing HB-LEDs in two branches of six LEDs each one. These kind of configurations supply output voltages of around $20 \mathrm{~V}$ and power levels around $12 \mathrm{~W}$. It is obvious that this application needs to be low-cost and small in size, in addition to having a high step-down ratio between input and output voltage, high efficiency and a sufficiently high PF.

This article presents a low-cost ac-dc HB-LED driver for retrofit bulb lamp applications conceived from a well-known concept: the use of a Loss-Free Resistor (LFR). In this case, however, the LFR is connected in series with the rectified mains to shape the line input current. Section II presents the development of this idea and its basic analysis. A static analysis including input current distortion analysis is then carried out in Section III using flyback converter as a LFR. This section also includes the development of a design procedure for the proposed ac-dc HB- 
LED driver. Finally, the experimental results of two $12 \mathrm{~W}$ prototypes are reported in Section IV with the aim of verifying the theoretical analysis presented previously. Finally, Section V concludes the article.

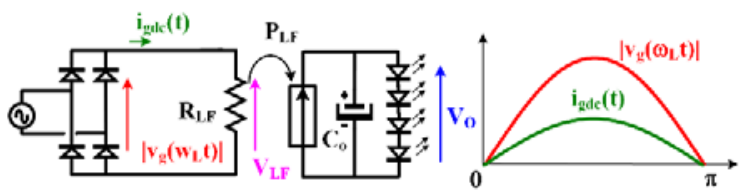

(a)
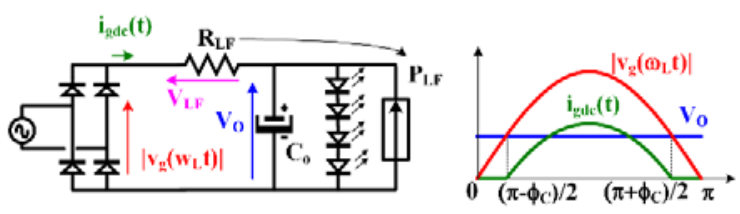

(b)

Figure 1. a) Traditional LFR configuration for designing PFCs (i.e. parallel with rectified mains); b) Proposed LFR configuration to shape the line input current (i.e. series with rectified mains).
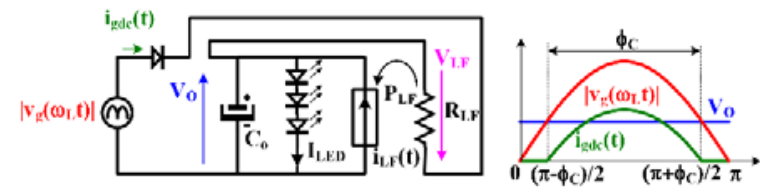

Figure 2. Equivalent circuit of the LFR configuration in series with the rectified mains to shape the line input current.

\section{USING A LOSS-FREE RESITOR (LFR) CONNECTED IN SERIES WITH THE RECTIFIED MAINS TO SHAPE THE LINE INPUT CURRENT.}

The concept of the LFR is very well known: this element is a two-port power-conservative network which emulates resistive characteristics at its input port and transfers power to its output port [11-14]. Traditionally, the LFR configuration in parallel with the rectified mains has been used massively in the design of PFCs (Fig. 1a). In this case, a sinusoidal input current is demanded from the mains. LFR performance is usually obtained by means of controlling a PWM converter operating in Continuous Conduction Mode (CCM) with two feedback loops (i.e., multiplier control [1517]). However, as the cost and the complexity of this solution are high, it is often used for high performance ac-dc HB-LED drivers [18]. Following the same configuration, some converters behave naturally as a LFR, however, without the need for two external feedback loops, thus reducing cost and complexity and making them ideal for low-cost applications (i.e. ac-dc HB-LED drivers for retrofit bulb lamp applications). Examples include the buck-boost, flyback, SEPIC, Zeta and Cuk converters operating in Discontinuous Conduction Mode (DCM). However, it is important to highlight that the use of Switching Mode Power Supply (SMPS) acting as a LFR introduces power losses. In this case, all the power is processed by the SMPS in order to supply load. Power losses can therefore reduce efficiency excessively if the SMPS is no efficient.
This is the main drawback of driving circuits massively used nowadays for retrofit bulb lamp applications (i.e. based on flyback converter). The most extended solution adopted is to operate at switching frequencies below $100 \mathrm{kHz}$ in order to obtain efficiencies around $82 \%$. Other well-known techniques applied to flyback converter (i.e. resonant behaviour [19], non-traditional controls [20], topology modifications, [21] active clamp [22], etc...) in order to obtain efficiencies around $88 \%$ can be used, however they have been obviated by manufactures due to the increase in the cost and complexity of the lamp . On the other side, in the last years some authors have been proposed more efficient topologies (i.e efficiencies around $89 \%$ ) based on asymmetrical half bridge flyback converter [23], two stage resonant buck converter [24], etc. However the cost and complexity of these circuits also penalize these solutions. Other drawback of flyback topology is the transformed used to obtain a high step-down ratio between the input and output voltage $\left(\mathrm{V}_{\mathrm{O}}\right)$, thereby increasing the size and cost of the configuration.

Another possibility is shown in Fig.1b: the use of a LFR in series with the rectified mains to shape the line input current. In this case, the total power transferred to the load is not equal to the average power processed by the LFR. Therefore, only a portion of the total input power is processed by the LFR. The other portion is transferred directly to the load (neglecting the losses introduced by the input rectifier). Lower power losses are hence introduced compared to the configuration with a SMPS acting as a LFR connected in parallel with the rectified mains. The proposed solution thus should increase efficiency.

As regards the shape of the input current, however, this solution does not generate a sinusoidal input current. Nevertheless, ac-dc HB-LED drivers for replacing incandescent bulb lamp are required to comply with more relaxed regulations (i.e., EN 61000-3-2 Class D and the ENERGY STAR ${ }^{\circledR}$ program) than their counterparts with a power level above $25 \mathrm{~W}$, and hence this type of input waveform can constitute a real alternative from the point of view of the distortion of the input current.

Figure 2 shows the equivalent circuit used to develop the theoretical study of the proposed configuration for the LFR. The input current of the circuit presented in Fig. 2 can be easily obtained:

$$
i_{g d c}(t)=\frac{v_{g}(t)-V_{O}}{R_{L F}}=\frac{V_{g p}\left|\sin \left(\omega_{L} t\right)\right|-V_{O}}{R_{L F}},
$$

where, $\omega_{\mathrm{L}}$ is the line angular frequency, $\mathrm{V}_{\mathrm{gp}}$ the peak value of the input voltage and $\mathrm{V}_{\mathrm{O}}$ is the output voltage. It should be noted that this expression is only valid for the interval $\left[\left(\pi-\phi_{C}\right) / 2,\left(\pi+\phi_{C}\right) / 2\right]$. During the rest of the line angle, $\omega_{\mathrm{L}} \mathrm{t}$, $\mathrm{i}_{\mathrm{gdc}}(\mathrm{t})$ becomes zero. The expression of $\phi_{\mathrm{C}}$ is obtained by equaling the line input voltage expression to zero at $\omega_{\mathrm{L}} \mathrm{t}=\left(\pi-\phi_{\mathrm{C}}\right) / 2$ :

$$
\phi_{C}=2 \cdot \arccos \left(\frac{V_{O}}{V_{g p}}\right) .
$$

The expression of the average input power as a function of the conduction angle $\left(\phi_{\mathrm{C}}\right)$ can be obtained from (1) and (2): 


$$
P_{g}=\frac{1}{\pi} \int_{\frac{\pi-\phi}{2}}^{\frac{\pi+\phi}{2}} i_{g d c}(t) \cdot v_{g p}\left|\sin \left(\omega_{L} t\right)\right| d\left(\omega_{L} t\right)=\frac{V_{g p}^{2}}{2 \pi R_{L F}}\left(\phi_{C}-\sin \left(\phi_{C}\right)\right) .
$$

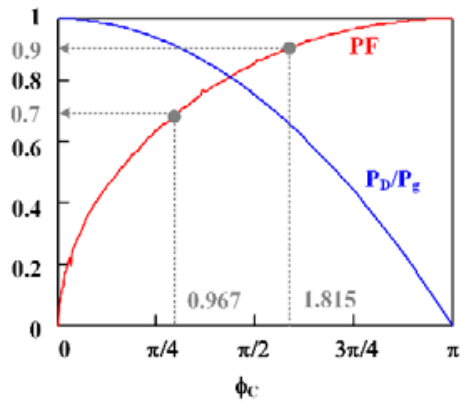

Figure 3. $\mathrm{PF}$ and $\mathrm{P}_{\mathrm{D}} / \mathrm{P}_{\mathrm{g}}$ versus the conduction angle.

By means of (1), (2) and (3), the rectified input current can be expressed as a function of the conduction angle:

$$
i_{g d c}(t)=\frac{2 P_{g} \cdot \cos \left(\frac{\phi_{C}}{2}\right)}{V_{O}} \frac{\left(2 \cdot\left|\sin \left(\omega_{L} t\right)\right|-\cos \left(\frac{\phi_{C}}{2}\right) \cdot \phi_{C}\right)}{\phi_{C}-\sin \left(\phi_{C}\right)} .
$$

However, as previously stated, only a portion of the total power is processed by LFR, $\mathrm{P}_{\mathrm{LF}}$, the other portion is transferred directly to the load, $\mathrm{P}_{\mathrm{D}}$ :

$$
P_{g}=P_{L F}+P_{D}
$$

Applying KCL (Kirchhoff's Current Law) and taking average values, we obtain:

$$
I_{L F}=I_{L E D}-I_{g d c} .
$$

where $I_{L F}$ is the average value of $i_{L F}(t)$ (see Fig. 2), $I_{L E D}$ is the dc current passing through the HB-LEDs and $\mathrm{I}_{\mathrm{gdc}}$ is the average value of $i_{\text {gdc }}(t)$ from (4). Igdc_value can be calculated as follows:

$$
I_{g d c}=\frac{1}{\pi} \int_{\frac{\pi-\phi}{2}}^{\frac{\pi+\phi}{2}} i_{g d c}(t) d\left(\omega_{L} t\right)=\frac{2 P_{g} \cos \left(\frac{\phi_{C}}{2}\right)}{V_{O}\left(\phi_{C}-\sin \left(\phi_{C}\right)\right.}\left(2 \sin \left(\frac{\phi_{C}}{2}\right)-\phi_{C} \cos \left(\frac{\phi_{C}}{2}\right)\right)
$$

Bearing in mind that $\mathrm{I}_{\mathrm{LED}}=\mathrm{P}_{\mathrm{g}} / \mathrm{V}_{\mathrm{o}}$, the value $\mathrm{I}_{\mathrm{LF}}$ can be easily obtained from (6) and (7):

$$
I_{L F}=\frac{P_{g}}{V_{O}}-I_{g d c}=\frac{P_{g}}{V_{O}\left(\phi_{C}-\sin \left(\phi_{C}\right)\right.}\left(\phi_{C}\left(2+\cos \left(\phi_{C}\right)\right)-3 \sin \left(\phi_{C}\right)\right)
$$

Figure 3 shows both the PF of the input current and the power directly supplied to the load normalized to the input power $\left(\mathrm{P}_{\mathrm{D}} / \mathrm{P}_{\mathrm{g}}\right)$ versus the conduction angle. As can be seen, as the conduction angle increases, the PF likewise increases due to the fact that the input current i s less distorted. However, if the conduction angle increases, the power directly transferred to the load from the mains decreases, thus increasing the power processed by the LFR and therefore decreasing the efficiency of the proposed solution, as stated previously. In order to design an ac-dc HB-LED driver based on the proposed solution (i.e., a LFR in series with the rectified mains shaping the input current), a trade-off must be made between compliance with international regulations and efficiency.
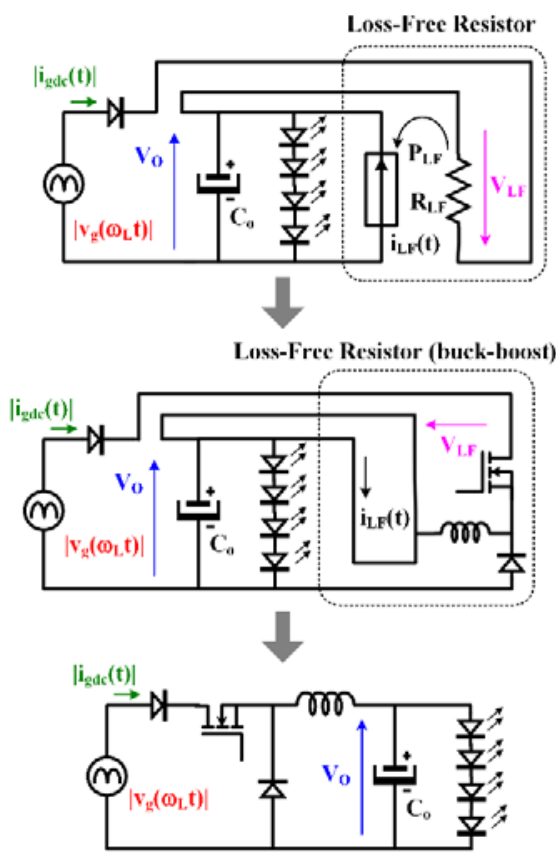

Figure 4. Deduction of the equivalent circuit of buck-boost converter used as a LFR connected in series with the rectified mains (i.e buck converter).

III. USING A FLYBACK TOPOLOGY AS A LFR CONNECTED IN SERIES WITH THE RECTIFIED MAINS TO DESIGN AN AC-DC HB-LED DRIVER

\section{A. Discontinuous Conduction Mode (DCM) operation.}

\section{1) Static analysis}

Continuing with the main idea of this paper (i.e., the proposal of a low-cost solution for designing an ac-dc HB-LED driver for retrofit lamp applications), the first option to implement a LFR with a switching power supply could be the buck-boost converter operating in DCM. As stated previously, this topology behaves as a natural LFR. If a buck-boost converter is used as a LFR in the proposed configuration (i.e. Fig. 2), then the ac-dc HB-LED driver becomes a buck topology operating in DCM (Fig.4). The buck converter is known to be the most efficient step-down topology at the lowest cost operating either in CCM or DCM. However, its efficiency decreases when a high step-down ratio is needed due to the fact that the duty cycle is very small at the peak value of the input voltage. As was before mentioned, some authors have presented solutions to this problem, subsequently increasing the cost and complexity of ac-dc HB-LED drivers [20].

At this point, the flyback converter operating in DCM becomes another interesting alternative option to be used as a LFR in the proposed configuration. Figure 5 shows the final circuit obtained from the application of the flyback converter as a LFR. This topology is very simple and uses few components. Furthermore, it provides a higher duty cycle than buck converter thanks to the turn ratio of its coupled inductor $\left(\mathrm{n}_{1}\right.$ and $\left.\mathrm{n}_{2}\right)$ when a 
high step-down ratio is needed. The expression of the value of $\mathrm{R}_{\mathrm{LF}}$ using a flyback converter operating in DCM as a LFR is wellknown ([11]):

$$
R_{L F}=\frac{2 L_{m} f_{S}}{d^{2}},
$$

where $\mathrm{L}_{\mathrm{m}}$ is the primary side magnetizing inductance of the flyback coupled inductor, $\mathrm{f}_{\mathrm{S}}$ is the switching frequency and $\mathrm{d}$ is the duty cycle.

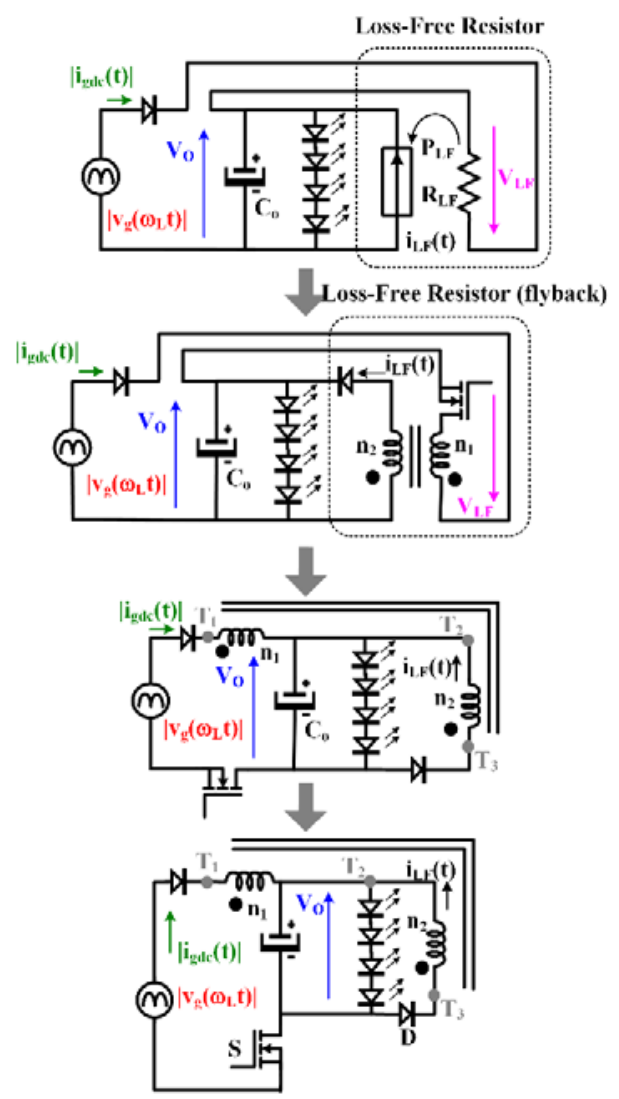

Figure 5. Deduction of the equivalent circuit of flyback converter used as a LFR connected in series with the rectified mains.

To ensure that the converter is operating in DCM, operation in Boundary Conduction Mode (BCM) must be imposed when the converter is operating at the lowest peak value of the line voltage, $\mathrm{V}_{\text {gpmin, }}$, and at maximum power, $\mathrm{P}$. The converter will thus operate in DCM in any other possible condition. At this point the static analysis of the proposed solution must be developed. Equivalent circuits during $\left[0, \mathrm{~d} / \mathrm{f}_{\mathrm{S}}\right]$ interval and $\left[\mathrm{d} / \mathrm{f}_{\mathrm{S}}, 1 / \mathrm{f}_{\mathrm{S}}\right]$ interval operating in $\mathrm{BCM}$ are shown in Fig. 6a and Fig. 6b respectively. During the first interval the power MOSFET is turned-on, and therefore, $\mathrm{L}_{\mathrm{m}}$ is charged by $\mathrm{v}_{\mathrm{g}}(\mathrm{t})-$ $\mathrm{V}_{\mathrm{O}}$. In the second interval $\mathrm{L}_{\mathrm{m}}$ is discharged by the output voltage. It is important to highlight that the coupled inductor is always supplying current to the load. Figure $6 \mathrm{c}$ shows the main current waveforms of this operation. Even though the static analysis of the proposed solution can be carried out by analyzing Fig. 6 circuits, we are going to base the proposed study only in the flyback converter placed in series with the rectified main in order to highlight the proposed concept of energy transfer. Applying Faraday's Law when the flyback converter operates in $\mathrm{BCM}$ at $\mathrm{V}_{\text {gpmin }}$, we obtain:

$$
\begin{aligned}
& i_{L_{\text {mpeak_vgp min }}}=\frac{V_{L F \min }}{L_{m}}\left(\frac{d_{\text {max }}}{f_{S}}\right)=\frac{V_{g p \min }-V_{O}}{L_{m}}\left(\frac{d_{\text {max }}}{f_{S}}\right), \\
& i_{\text {Lmpeak_vg min }_{\text {m }}}=\frac{n_{1}}{n_{2}} \frac{V_{O}}{L_{m}} \frac{\left(1-d_{\text {max }}\right)}{f_{S}}=\frac{1}{n} \frac{V_{O}}{L_{m}} \frac{\left(1-d_{\text {max }}\right)}{f_{S}},
\end{aligned}
$$

where $\mathrm{n}=\mathrm{n}_{2} / \mathrm{n}_{1}$, being $\mathrm{n}_{1}$ and $\mathrm{n}_{2}$ are the number of turns of the primary and secondary winding of the couple inductor, respectively, $\mathrm{V}_{\mathrm{LFmin}}$ is the input voltage of the flyback converter operating as a LFR (i.e., $V_{L F m i n}=V_{\text {gpmin }}-V_{0}$, see Fig. 5) and $d_{\max }$ is the maximum value of the duty cycle when the peak value of $\mathrm{v}_{\mathrm{g}}(\mathrm{t})$ is $\mathrm{V}_{\text {gpmin. }}$. Using (10) and (11), we obtain the expression of the maximum value of the duty cycle:

$$
d_{\max }=\frac{V_{O}}{n V_{g p \min }+(1-n) V_{O}}=\frac{M_{\max }}{n+(1-n) M_{\max }},
$$

where $\mathrm{M}_{\max }=\mathrm{V}_{\mathrm{O}} / \mathrm{V}_{\text {gpmin }}$.

The average line current (averaged over a switching period, see Fig. 6) at the peak value of the minimum line voltage, $\mathrm{i}_{\text {gdc peakmax }}$, can be easily calculated from (1):

$$
i_{g d c_{-} \text {peak } \max }=\frac{V_{g p \min }-V_{O}}{R_{L F \min }},
$$

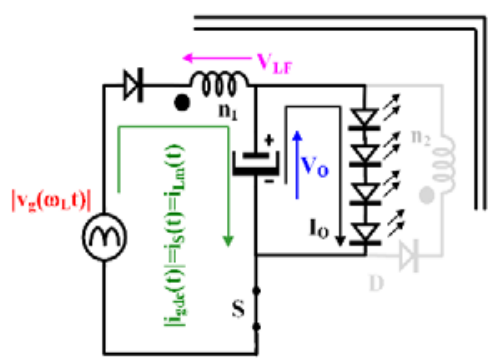

(a)

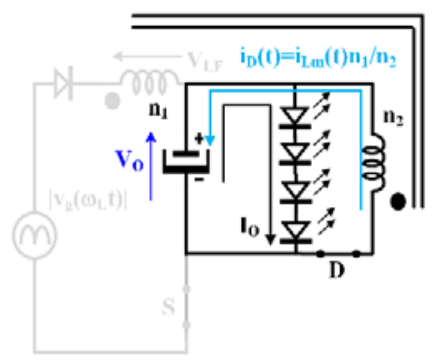

(b)

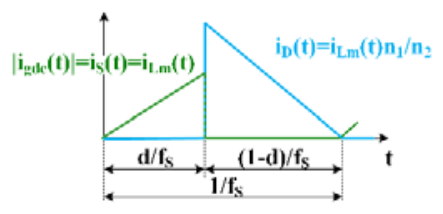

(c)

Figure 6. a) Equivalent circuit of the proposed solution operating in BCM during $\left[0, d / f_{s}\right]$ interval. b) Equivalent circuit of the proposed solution operating in $\mathrm{BCM}$ during $\left[\mathrm{d} / \mathrm{f}_{\mathrm{S}}, 1 / \mathrm{f}_{\mathrm{S}}\right]$ interval. c) Main current waveforms. 
where $\mathrm{R}_{\mathrm{LFmin}}$ is the minimum value of LFR, which corresponds to operation at the minimum value of the line voltage and full load. In this condition, the conduction angle presents the maximum possible value, i.e., $\phi_{\text {Cmax }}$. The value of $R_{L F m i n}$ can be easily calculated from (3):

$$
R_{L F \min }=\frac{V_{g p \min }^{2}}{2 \pi P_{g}}\left(\phi_{C \max }-\sin \left(\phi_{C \max }\right)\right) .
$$

Due to operation in BCM in the aforementioned conditions, the relationship between $i_{g d c}$ peakmax and $i_{\text {Lmpeak_vgmin }}$ (see Fig. 7) must verify:

$$
i_{\text {gdc_peak } \max }=\frac{i_{L_{\text {Lmpeak_vgp } \min }}}{2} d_{\text {max }} .
$$

Using (10), (13) and (15), we obtain the value of $\mathrm{L}_{\mathrm{m}}$ which assures DCM operation of the flyback converter in series with the rectified mains (i.e. LFR behaviour due to the fact that $\mathrm{L}_{m}$ ensures operation in $\mathrm{BCM}$ at the minimum line voltage and maximum power, and hence operation in DCM when the current passing through the converter is lower):

$$
L_{m}=\frac{R_{L F \min } \cdot d_{\max }^{2}}{2 f_{S}} .
$$

It should be noted that (16) is a particular case of (9) applied in the aforementioned conditions. Finally, from (12), (14) and (16), we obtain the expression of $\mathrm{L}_{\mathrm{m}}$ as a function of the specifications of our ac-dc HB-LED driver:

$$
L_{m}=\frac{V_{o}^{2}}{4 \pi P_{g} f_{s}}\left(\frac{1}{n+(1-n) M_{\text {max }}}\right)^{2}\left(2 \arccos \left(M_{\max }\right)-\sin \left(2 \arccos \left(M_{\max }\right)\right)\right) .
$$

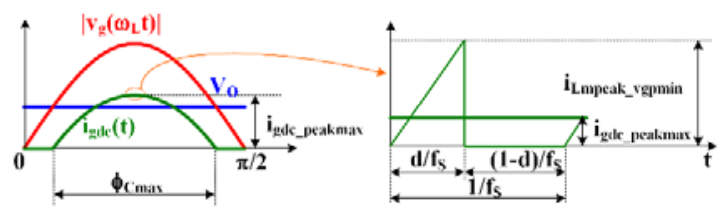

Figure 7. Relationship between $i_{\text {gdc_peakmax }}$ and iLmpeak_vgpmin.

At this point, the expression of the duty cycle at any operation point can be obtained from (2), (3), (9) and (16):

$$
d=\sqrt{\frac{\left(2 \arccos \left(M_{\max }\right)-\sin \left(2 \arccos \left(M_{\max }\right)\right)\right)}{(2 \arccos (M)-\sin (2 \arccos (M)))}}\left(\frac{1}{n+(1-n) M_{\max }}\right),
$$

where $\mathrm{M}$ is equal to $\mathrm{V}_{\mathrm{O}} / \mathrm{V}_{\mathrm{gp}}$. Figure 8 shows the evolution of the duty cycle versus $M$ for different values of $n$ both for an American design of a HB-LED driver for retrofit lamp applications with an output voltage of $20 \mathrm{~V}$ (i.e., $\mathrm{M}_{\max }=20 /(90 \sqrt{2})$ and $(20 /(130 \sqrt{2}))<\mathrm{M}<(20 /(90 \sqrt{2})))$ and for a European design with an output voltage of $20 \mathrm{~V}$ (i.e., $\mathrm{M}_{\max }=20 /(190 \sqrt{2})$ and $(20 /(265 \sqrt{2}))<M<(20 /(190 \sqrt{2})))$. As can be seen, the duty cycle value decreases as $M$ decreases and $n$ increases. Moreover, the duty cycles are greater for an American design than for a European design. However, the plots do not show excessive low values of the duty cycle, allowing this solution for high step-down ratio applications.
TABLE I. MAXIMUM OUTPUT VOLTAGES FOR THE AMERICAN AND EUROPEAN MAINS SUPPLY COMPLYING WITH INTERNATIONAL REGULATIONS

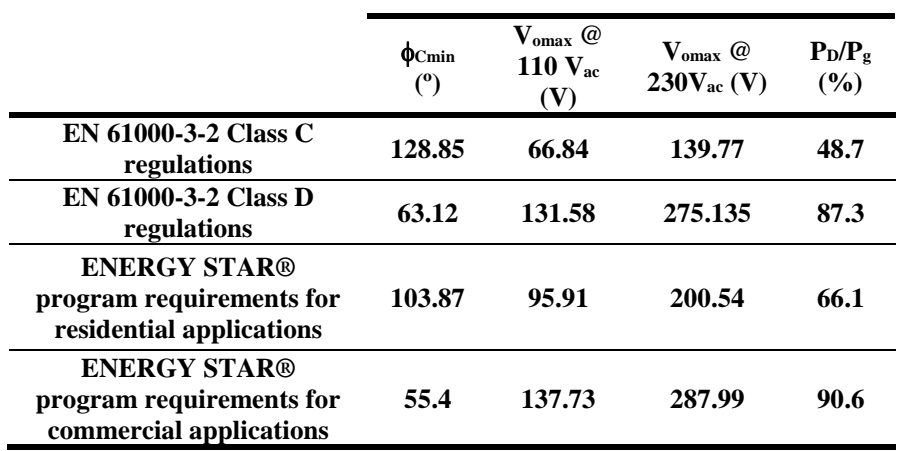

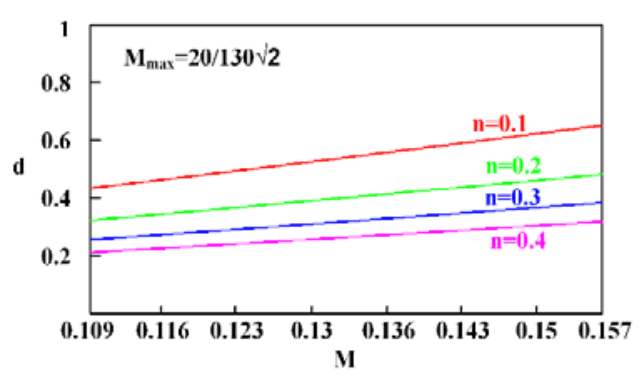

(a)

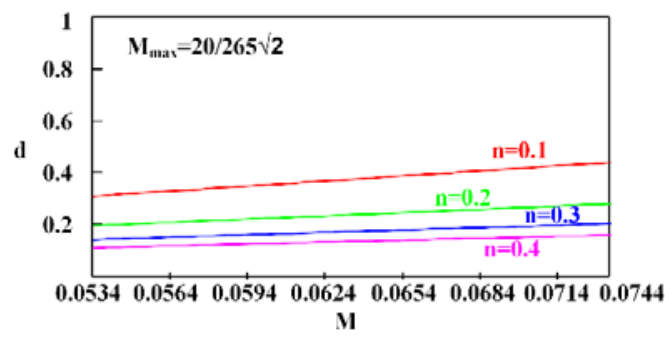

(b)

Figure 8. Evolution of d versus $M$ for different values of n; a) American design; b) European design.

2) Desing procedure

We are now ready to design the ac-dc HB-LED driver. The goal is to obtain the key parameters of the flyback converter (i.e. $\mathrm{n}, \mathrm{L}_{\mathrm{m}}$ and the output capacitor, $\mathrm{C}_{\mathrm{o}}$ ). The design inputs are the output voltage, $\mathrm{V}_{\mathrm{O}}$, the peak value of the input voltage, $\mathrm{V}_{\mathrm{gp}}$ (i.e., $\left.\mathrm{V}_{\text {gpnax }}, \mathrm{V}_{\text {gpnom, }} \mathrm{V}_{\mathrm{gpmin}}\right)$, the input power, $\mathrm{P}_{\mathrm{g}}$, the line frequency, $\omega_{\mathrm{L}}$, and the switching frequency, $\mathrm{f}_{\mathrm{s}}$.

First, the $\phi_{C}$ value must be checked to verify it complies with international regulations due to the fact that $\phi_{\mathrm{C}}$ is imposed by the application (i.e., it is imposed by $\mathrm{V}_{\mathrm{gp}}$ and $\mathrm{V}_{\mathrm{O}}$ ). In other words, $\phi_{\mathrm{C}}$ must be greater than $63.12^{\circ}$ to comply with EN 61000-3-2 Class D regulations [25-27], greater than $128.85^{\circ}$ to comply with EN 61000-3-2 Class C regulations [25-27], greater than $103.87^{\circ}$ to comply with the ENERGY STAR $\AA$ program for residential applications (PF $>0.9$, Fig. 3) and greater than $55.4^{\circ}$ to comply with the ENERGY STAR ${ }^{\circledR}$ program for commercial applications 
(PF $>0.7$, Fig. 3). These conduction angles determine the maximum output voltage complying with international regulations according to (2). Table I shows these maximum output voltages for the American and European mains supply. We therefore only need to check that the output voltage of the application is lower than the values shown in Table I.

Second, the power processed by the LFR (i.e., $\mathrm{P}_{\mathrm{LF}}$ ) can be easily calculated by means of $\phi_{\mathrm{C}}$ and $\mathrm{P}_{\mathrm{g}}$ using Fig. 3. Following the same procedure, Table I shows the percentage of power directly supplied to the load, $\mathrm{P}_{\mathrm{D}}$, with respect to the input power, $\mathrm{P}_{\mathrm{g}}$, for the maximum output voltage complying with international regulations.

Third, choose $\mathrm{n}$ according to a trade-off between the voltage stress in both the power transistor and diode under the minimum duty cycle. As in any topology with galvanic isolation belonging to the buck-boost family of converters, the voltage across the main switch and the diode must be bounded. For this reason, these voltages, which depend on the value of $n$, may constitute a design constraint. The expressions of these voltages (voltage of the main switch, $v_{S}$, and voltage of the diode, $v_{D}$ ) normalized to the output voltage $\left(v_{S_{-} n}\right.$ and $\left.v_{D_{-} n}\right)$ can be easily calculated taking into account the final circuit of Fig 5 .

$$
\begin{aligned}
& v_{S_{-} n}=\frac{v_{S}}{V_{O}}=\frac{1}{M}+\frac{1-n}{n}, \\
& v_{D_{-} n}=\frac{v_{D}}{V_{O}}=\frac{n}{M}+(1-n) .
\end{aligned}
$$

Figure 9 shows the evolution of $v_{D_{-} n}$ and $v_{S_{n} n}$ versus $M$ for different values of $\mathrm{n}$ both for an American design of a HB-LED driver for retrofit lamp applications with an output voltage of 20 $\mathrm{V}$ (i.e., $\mathrm{M}_{\max }=(20 /(90 \sqrt{2}))$ and $\left.(20 /(130 \sqrt{2}))<\mathrm{M}<(20 /(90 \sqrt{2}))\right)$ and for a European design with an output voltage of $20 \mathrm{~V}$ (i.e. $\mathrm{M}_{\max }=(20 /(190 \sqrt{2})) \quad$ and $\left.\quad(20 /(265 \sqrt{2}))<\mathrm{M}<(20 /(190 \sqrt{2}))\right)$.

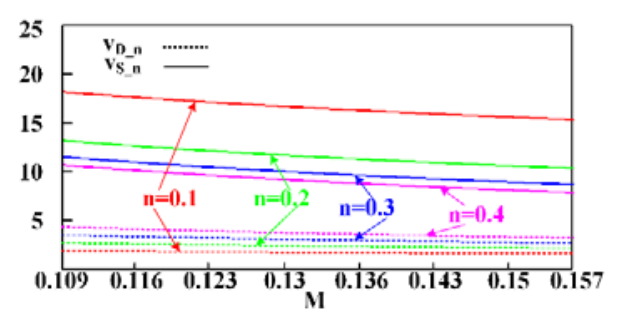

(a)

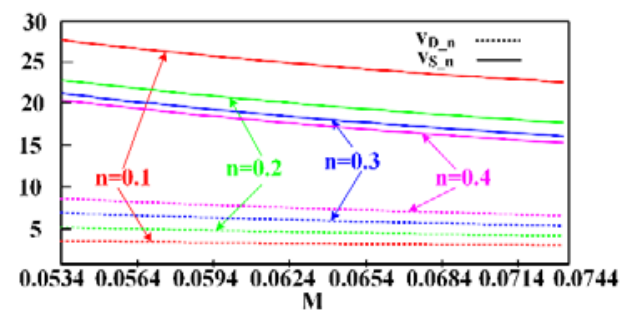

(b)

Figure 9. Evolution of $\mathrm{v}_{\mathrm{S}_{-} \mathrm{n}}$ and $\mathrm{V}_{\mathrm{D}_{-} \mathrm{n}}$ versus $\mathrm{M}$ for different values of $\mathrm{n}$; a) American design; b) European design.
Furthermore, $\mathrm{n}$ must be chosen to obtain a minimum duty cycle (corresponding to the minimum peak value of the input voltage and current) as high as possible to optimize the efficiency. It is evident that not all the aforementioned requirements can be met at the same $n$ value; therefore, a trade-off design solution must be adopted.

Fourth, the value of $\mathrm{L}_{\mathrm{m}}$ must be chosen in order to guarantee operation in $\mathrm{BCM}$ at minimum line voltage and maximum power and hence operation in DCM when the current passing through the converter is lower (i.e., in the remaining operating conditions) using expression (17).

Finally, assuming that all the output power of the HB-LED driver must be filtered by output capacitor in order to obtain a dc current trough the HB-LEDs string, the output capacitor $\left(\mathrm{C}_{\mathrm{o}}\right)$ can be calculated in order to reduce the twice the line frequency ripple of the output current.

\section{B. Boundary Conduction Mode (BCM) operation.}

\section{1) Static analysis an input current distortion analysis}

In order to obtain a good trade-off between switching losses and conduction losses so as to optimize efficiency, in recent years some authors have proposed the BCM with the aim of achieving the best performance between switching losses and conduction losses at low power levels. This operation mode has been widely applied in ac-dc topologies to increase the efficiency of HB-LED drivers [28-30]. Therefore, the efficiency of the aforementioned solution (i.e., a flyback converter operating in DCM acting as a LFR connected in series with the rectified mains) can be improved by changing the operation mode to BCM. However, if a flyback operating in BCM is used as a LFR, then the proposed solution is different. In this case, expression (9) is also valid, but

$\mathrm{R}_{\mathrm{LF}}$ is not constant, because, even though the transistor conduction period, $t_{o n}$, is constant, the switching frequency, $f_{s}(t)$, varies with the line angle, $\omega_{\mathrm{L}} \mathrm{t}$ in order to operate in BCM. This implies that, if we want to present this solution as a real alternative, the input current is not sinusoidal for the interval $\left[\left(\pi-\phi_{\mathrm{C}}\right) / 2\right.$, $\left.\left(\pi+\phi_{\mathrm{C}}\right) / 2\right]$, thus introducing distortion. Accordingly, a static analysis and an input current distortion analysis of the flyback converter operating in BCM used as a LFR connected in series with the rectified mains will be carried out in this section.

Faraday's law applied to both the transistor $\left(\mathrm{t}_{\mathrm{on}}\right)$ and the diode $\left(\mathrm{t}_{\mathrm{off}}\right)$ conduction periods yields:

$$
\begin{aligned}
& i_{\text {Lmpeak }}(t)=\frac{V_{g p}\left|\sin \left(\omega_{L} t\right)\right|-V_{O}}{L_{m}} t_{\text {on }}, \\
& i_{\text {Lmpeak }}(t)=\frac{n_{1}}{n_{2}} \frac{V_{O}}{L_{m}} t_{\text {off }},
\end{aligned}
$$

where $i_{\text {Lmpeak }}(t)$ is the peak value of the current through the magnetizing inductance of the flyback coupled inductor referred to the primary side.

Using (21), (22) and the BCM condition (i.e., $1 / \mathrm{f}_{\mathrm{S}}(\mathrm{t})=$ $\mathrm{t}_{\mathrm{on}}+\mathrm{t}_{\mathrm{off}}$ ), the switching frequency and the LFR can be expressed as:

$$
f_{S}(t)=\frac{M}{(1-n) M+n\left|\sin \left(\omega_{L} t\right)\right|} \frac{1}{t_{\text {on }}}=\frac{1}{\Omega_{L F}(t)} \frac{1}{t_{\text {on }}},
$$




$$
R_{L F}(t)=2 L \cdot t_{o n} \cdot\left[\frac{(1-n) M+n\left|\sin \left(\omega_{L} t\right)\right|}{M}\right]=2 L \cdot t_{o n} \cdot \Omega_{L F}(t) .
$$

Now, $R_{L F}$ is not constant as previously stated. The evolution of the shape of $R_{F L}$ (i.e., $\Omega_{\mathrm{LF}}$ ) versus the line angle $\left(\omega_{\mathrm{L}} \mathrm{t}\right)$ is shown in Fig 10. As can be seen, $\mathrm{R}_{\mathrm{FL}}$ varies with the line angle due to the fact that variable frequency operation is used to operate in $\mathrm{BCM}$ (i.e., constant $t_{\text {on }}$ and variable $\mathrm{f}_{\mathrm{S}}(\mathrm{t})$ ). In addition, Fig. 11 shows the maximum value of $R_{L F}$, which occurs at $\omega_{\mathrm{L}} t=\pi / 2$, normalized to the minimum value of $R_{L F}$, which occurs at $\omega_{L} t=\left(\pi-\phi_{C}\right) / 2$. This normalized value represents the level of variation of $\mathrm{R}_{\mathrm{LF}}$. As can be seen in Fig. 11, this variation is not negligible for different values of $\mathrm{M}$ and $\mathrm{n}$. We can therefore conclude that the effect of the variation of $\mathrm{R}_{\mathrm{LF}}$ on input current distortion needs to be analyzed.
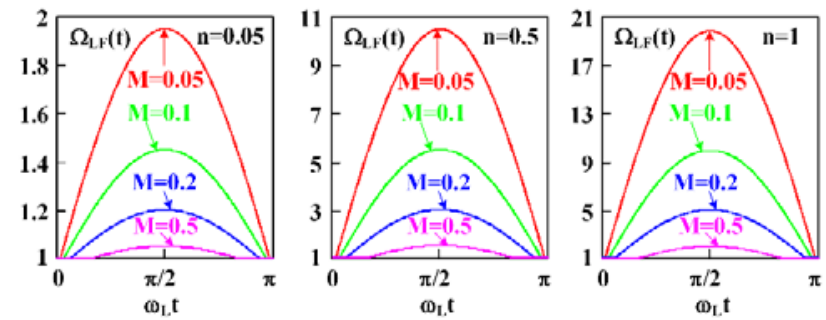

Figure 10. Evolution of $\Omega_{\mathrm{LF}}$ value versus ( $\left.\omega_{\mathrm{L}} \mathrm{t}\right)$ for different values of $\mathrm{M}$ and $n$.

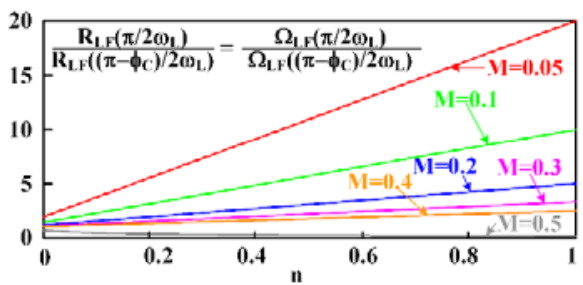

Figure 11. Maximum value of $\mathrm{R}_{\mathrm{LF}}$ normalized to the minimum value of $\mathrm{R}_{\mathrm{LF}}$ for different values of $\mathrm{M}$ and $\mathrm{n}$.

Using (1), (24) and the expressions of $M$ and $n$, the average input current in a switching period is:

$$
i_{g d c}(t)=\frac{V_{O}}{2 L}\left(\frac{d}{f_{s}}\right) \cdot\left[\frac{1}{(1-n) M+n\left|\sin \left(\omega_{L} t\right)\right|}\right]\left(\left|\sin \left(\omega_{L} t\right)\right|-M\right) .
$$

As can be seen in (25), the average input current is nonsinusoidal. It should be noted that this expression is only valid for the interval $\left[\left(\pi-\phi_{C}\right) / 2,\left(\pi+\phi_{C}\right) / 2\right]$. The rest of the line angle $\left(\omega_{\mathrm{L}} \mathrm{t}\right)$, $i_{\text {gdc }}(t)$ becomes zero. However, $i_{\text {gdc }}(t)$ can be highly sinusoidal for before mentioned interval for certain values of $M$ and $n$, as can be seen in Fig. 12.

The expression of the PF and THD of $\mathrm{i}_{\text {gdc }}(\mathrm{t})$ can be derived from (25). In this case, transcendent equations are obtained, which need to be solved numerically. Figures $13 \mathrm{a}$ and $13 \mathrm{~b}$ respectively show the plots of PF and THD versus $M$ for different values of $\mathrm{n}$. Even if $\mathrm{M}$ increases, the distortion of the input current remains low for realistic values of $n$ with respect to retrofit lamp applications.
Continuing with the input current distortion analysis, Fig. 14 shows the maximum value of $M$ that complies with this regulation versus $\mathrm{n}$ for both residential and commercial applications (i.e. ENERGY STAR ${ }^{\circledR}$ regulations).
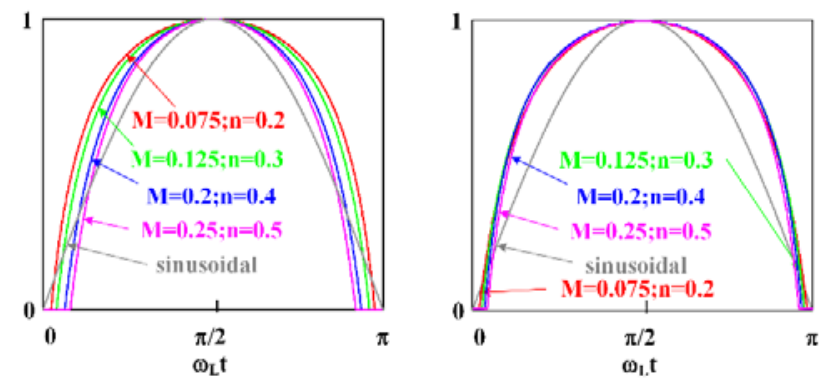

Figure 12. Normalized line input current versus the line angle for different values of $M$ and $n$.

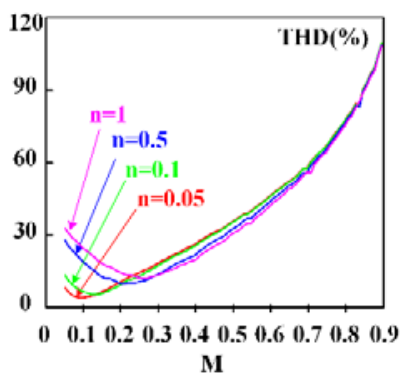

(a)

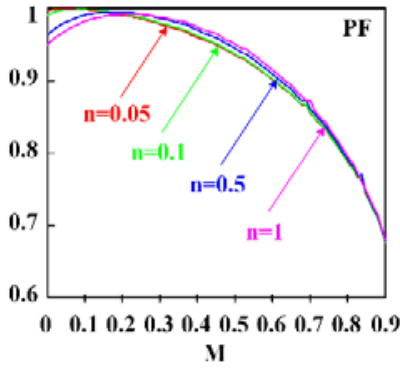

(b)
Figure 13. a) PF for different values of $M$ and $n$. b) THD for different values of $\mathrm{M}$ and $\mathrm{n}$.

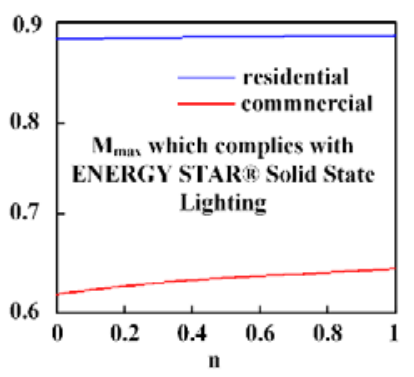

Figure 14. Maximum value of M complying with ENERGY STAR® regulations versus $n$

For Class D regulations (EN 61000-3-2), however, the imposed limits refer to the power processed by the ac-dc HB-LED driver. We must therefore continue the static study by calculating the average input power using (25):

$$
P_{g}=\frac{1}{\pi} \int_{0}^{\pi} i_{g d c}(t) \cdot V_{g p} \cdot\left|\sin \left(\omega_{L} t\right)\right| \cdot d\left(\omega_{L} t\right)=\frac{V_{o}^{2}}{2 L} t_{o n} \cdot \Pi_{L F},
$$

where $\Pi_{\mathrm{LF}}$ is: 


$$
\Pi_{L F}=\frac{1}{\pi \cdot M} \int_{0}^{\pi}\left[\frac{1}{(1-n) M+n\left|\sin \left(\omega_{L} t\right)\right|}\right]\left(\left|\sin \left(\omega_{L} t\right)\right|-M\right) \cdot\left|\sin \left(\omega_{L} t\right)\right| \cdot d\left(\omega_{L} t\right)
$$

Figure 15 shows the values of $\Pi_{L F}$ for different $M$ and $n$ values. Using the value of $\Pi_{\mathrm{LF}}$ in (26) and taking into account (25), a transcendent equation can be obtained for every harmonic normalized to the average input power, $\mathrm{P}_{\mathrm{g}}$. The Class $\mathrm{D}$ limits can thus be calculated. Figure 16 shows a plot of the rms value of each harmonic of the input current (from the $3^{\text {rd }}$ to the $13^{\text {th }}$ ) normalized to the average input power versus $M$ for different values of $n$. The Class D limit is likewise shown in each plot in gray. As can be seen, the rms value of each harmonic converges for different $n$ values at high values of $\mathrm{M}$. The Class $\mathrm{D}$ limits (in gray) defines the compliance for these high $\mathrm{M}$ values, as can be seen in Fig. 16. Therefore, the M limit to comply with Class D regulations is the same for all values of $n$. Each plot introduces a maximum $M$ value for each harmonic; however, the $11^{\text {th }}$ harmonic imposes the maximum $M$ value with respect to the input current $\left(\mathrm{M}_{\max }=0.84\right)$. The harmonics above the $13^{\text {th }}$ were also analyzed, but the harmonic content are negligible compared to the limits imposed by Class D regulations.

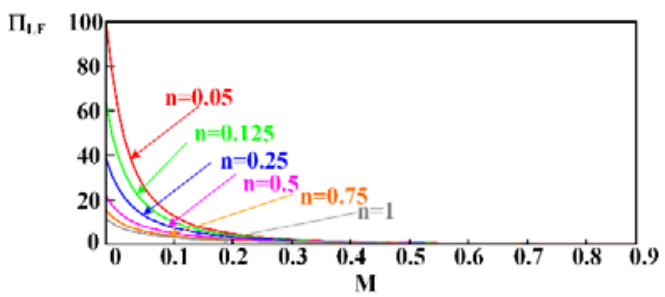

Figure 15. $\Pi_{\mathrm{LF}}$ values for different values of $\mathrm{M}$ and $\mathrm{n}$

Finally, using the $\Pi_{\mathrm{LF}}$ value, both $\mathrm{R}_{\mathrm{LF}}$ and the switching frequency expressions can be rewritten using (24) and (27):

$$
\begin{aligned}
& R_{L F}(t)=\frac{\Pi_{L F} V_{O}^{2}}{P_{g}} \cdot \Omega_{L F}(t), \\
& f_{S}(t)=\frac{\Pi_{L F} V_{O}^{2}}{2 L_{m} P_{g}} \cdot \frac{1}{\Omega_{L F}(t)} .
\end{aligned}
$$

\section{2) Desing procedure}

We are now ready to design the ac-dc HB-LED driver. The goal is to obtain the key parameters of the flyback converter (i.e. $\mathrm{n}, \mathrm{L}_{\mathrm{m}}$ and the output capacitor, $\mathrm{C}_{\mathrm{o}}$ )The inputs for this design are: the output voltage, $V_{\mathrm{O}}$, the peak value of the input voltage, $\mathrm{V}_{\mathrm{gp}}$, the input power, $\mathrm{P}_{\mathrm{g}}$, the line frequency, $\omega_{\mathrm{L}}$, and the minimum switching frequency, $\mathrm{f}_{\mathrm{Smin}}$.

First, $\mathrm{n}$ must be chosen in accordance with a trade-off between current and voltage stress in both the power transistor and diode, as stated in the previous design procedure. At this point, either (19) or (20) can be used (i.e., Fig. 9a or Fig. 9b).

Second, check that the ac-dc HB-LED design complies with international regulations (i.e., $M$ and $n$ verification of both $E N$ 6100-3-2 Class D via Fig. 14 and the ENERGY STAR ${ }^{\circledR}$ program via Fig. 16). Concluding the input current distortion analysis, a highly sinusoidal input current can be assumed for realistic designs. Once the compliance is checked, $\phi_{\mathrm{C}}$ can be calculated using (2), and therefore, power processed by the LFR (i.e., $P_{L F}$ ) is easily obtained by Fig. 3 .
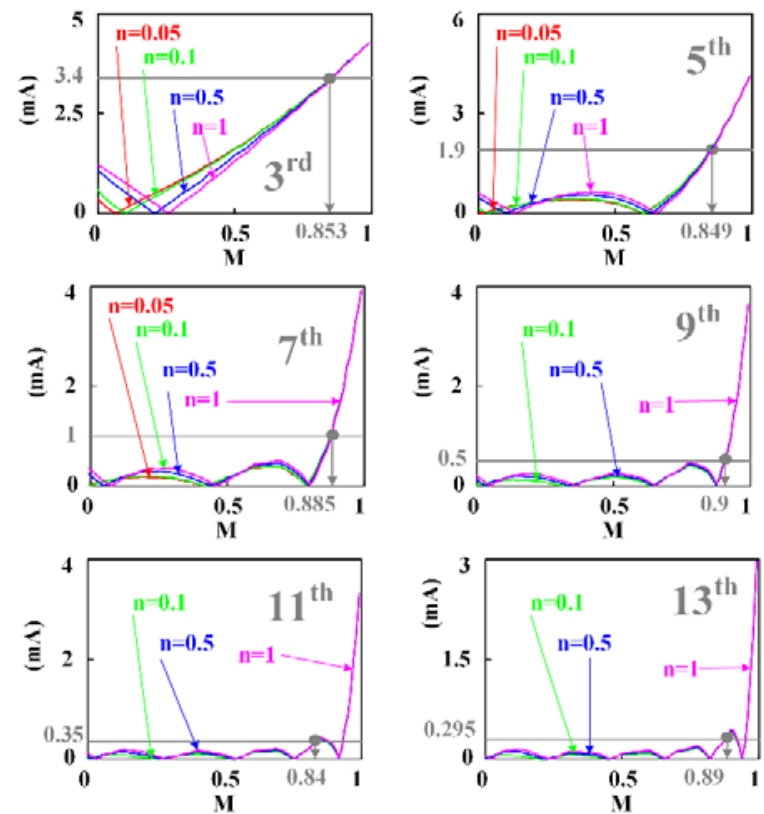

Figure 16. Evolution of the rms value of the $3^{\text {rd }}, 5^{\text {th }}, 7^{\text {th }}, 9^{\text {th }}, 11^{\text {th }}$ and $13^{\text {th }}$ harmonics of the input current normalized to the input power for different values of $\mathrm{M}$ and $\mathrm{n}$.

Third, once $M$ and $n$ are chosen, $\Omega_{\mathrm{LF}}(\mathrm{t})$ and $\Pi_{\mathrm{LF}}$ can be calculated using (23) and (27). At this point, the value of $\mathrm{L}_{\mathrm{m}}$ should be chosen so as to guarantee that the minimum switching frequency (at the peak value of the line voltage) will not be too low. Using (24) and (27) (i.e. Fig. 15):

$$
L_{m}=\frac{\Pi_{L F} V_{O}^{2}}{2 P_{g} f_{\text {min }}} \cdot \frac{1}{\Omega_{L F}\left(t=\frac{\pi}{2 \omega_{L}}\right)}=\frac{\Pi_{L F} V_{O}^{2}}{2 P_{g} f_{S \min }} \frac{M}{n+M(1-n)} .
$$

Fourth, the maximum switching frequency (at intervals around zero crossing of the input voltage) should not be too high. Its value must hence be checked. This value can be easily calculated from (28) and (24) (i.e. Fig. 11).

$$
f_{S \max }=f_{S \min } \frac{R_{L F}\left(t=\frac{\pi}{2 \omega_{L}}\right)}{R_{L F}\left(t=\frac{\pi-\phi_{C}}{2 \omega_{L}}\right)}=f_{S \min } \frac{\Omega_{L F}\left(t=\frac{\pi}{2 \omega_{L}}\right)}{\Omega_{L F}\left(t=\frac{\pi-\phi_{C}}{2 \omega_{L}}\right)} .
$$

At this point, once $\mathrm{L}_{m}$ has been chosen, the value of $t_{o n}$ can be calculated using (26). Check that the minimum duty cycle at $\omega_{L} t=\pi / 2$ and $V_{\text {gpmin }}$ is high enough to optimize efficiency using (23).

Finally, assuming a sinusoidal input current due to the high PF and low THD, $\mathrm{C}_{\mathrm{o}}$ can be calculated as was mentioned in Section III.A.2. 


\section{EXPERIMENTAL RESULTS}

A. Verification of LFR connected in series with the rectified mains concept.

A prototype of a flyback converter operating in DCM has been built in order to check the theoretical study presented in Section II. The rated operating conditions are: $\mathrm{V}_{\mathrm{gp}} / \sqrt{2}=110 \mathrm{~V}_{\mathrm{O}}=24 \mathrm{~V}$ and $\mathrm{P}_{\mathrm{g}}=10-70 \mathrm{~W}$. Figure 17 shows in red color the experimental efficiency results of the flyback converter connected in parallel with the rectified mains versus the input power. If the flyback converter is connected in series with the rectified mains, using (2) and Fig. 3, the conduction angle and the power directly supplied to the load normalized to the input power can be calculated (i.e. $\phi=2.51 \mathrm{rad}$ and $\mathrm{P}_{\mathrm{D}} / \mathrm{P}_{\mathrm{g}}=0.361$ ). At this point, using the data of the experimental efficiency of the flyback converter connected in parallel with the rectified mains ( $\eta_{\text {LFR }}$ ) $)$, the theoretical value of the efficiency of the flyback converter in series with the rectified main $\left(\eta_{\text {LFR_s }}\right)$ can be calculated:

$$
\eta_{\mathrm{LFR}_{-} s}\left(\mathrm{P}=\mathrm{P}_{\mathrm{g}}\right)=\left(\frac{\mathrm{P}_{\mathrm{D}}}{\mathrm{P}_{\mathrm{g}}}\right)+\cdot\left(1-\frac{\mathrm{P}_{\mathrm{D}}}{\mathrm{P}_{\mathrm{g}}}\right) \cdot \eta_{\mathrm{LFR}_{-} \mathrm{s}}\left(\mathrm{P}=1-\frac{\mathrm{P}_{\mathrm{D}}}{\mathrm{P}_{\mathrm{g}}}\right) \text {. }
$$

Figure 17, shows both the theoretical and experimental values of $\eta_{\text {LFR_s. }}$ As you can see, they are very close, verifying the theoretical study presented in Section II and highlighting the improvement in efficiency by placing the LFR (i.e flyback operating in DCM) in series with the rectified mains.

\section{a) US HB-LED driver design}

The rated operating conditions of the first prototype are: $\mathrm{V}_{\mathrm{gp}} / \sqrt{ } 2=90-130 \mathrm{~V}_{\mathrm{O}}=22.5 \mathrm{~V}$ (i.e., $\left.\mathrm{M}=(22.5 /(110 \sqrt{ } 2))=0.128\right)$ $\mathrm{I}_{\mathrm{o}}=0.5 \mathrm{~A}$ (output current) and $\mathrm{P}_{\mathrm{g}}=12.5 \mathrm{~W}$. The ratio $\mathrm{n}=0.44$ was calculated following the design procedure presented in Section III.B.2 Furthermore, $\mathrm{L}_{\mathrm{m}}=600 \mu \mathrm{H}$ was calculated in order to guarantee a minimum switching frequency higher than audible frequency (i.e., $\mathrm{f}_{\mathrm{Smin}}=60 \mathrm{kHz}$ ). With this data, the maximum switching frequency is $215 \mathrm{kHz}$, which is not too high and it does not penalize efficiency by increasing switching losses.

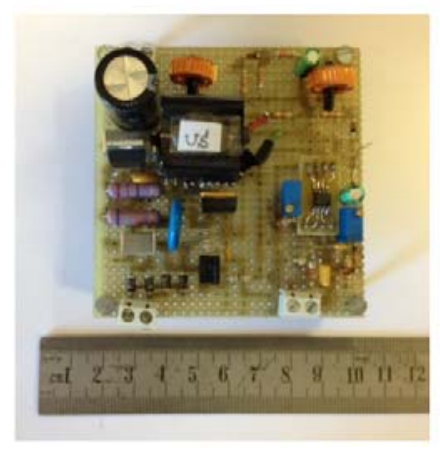

(a)

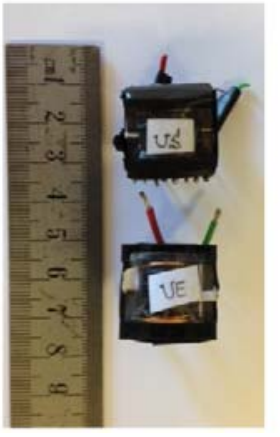

(b)

Figure 18. a) Experimental prototype. b) Couple inductor designs (i.e. US and EU).

TABLE II. LIST OF COMPONENTS OF THE HB-LED DRIVER

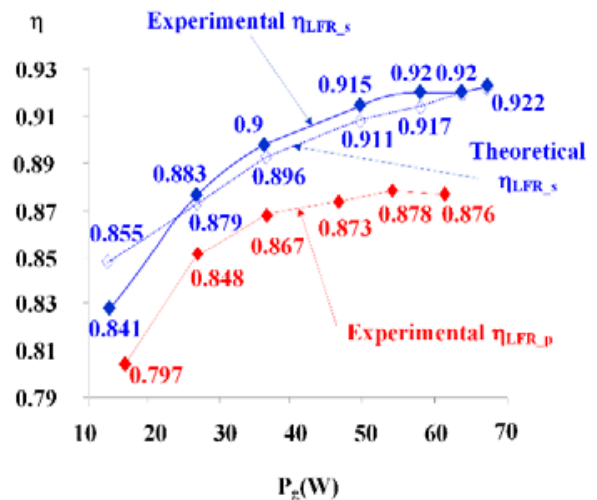

Figure 17. Efficiency versus input power for the LFR connected both in series and in parallel with the rectified mains.

\section{B. HB-LED driver designs}

Two prototypes of the proposed ac-dc HB-LED driver were built and tested. The unique difference between them is the couple inductor design. Figure 18 shows the photo of the prototype including both coupled inductor designs. The main circuit components are listed in Table II. They were controlled so as to operate in BCM using a commercial IC (NCL30000 by ON Semiconductors). The circuits have been performed using both an EMI filter to test the line input current and MOSFET snubbers to reduce the ringing in both the MOSFET and the diode. In this case, the output current rather than the output voltage is controlled. Finally, the converter output is connected to a string of 7 LXK2PW14T00 HB-LEDs (Luxeon). put $200 \mathrm{nF} / 400 \mathrm{~V}$ MKP EPCOS

\begin{tabular}{|c|c|}
\hline $\begin{array}{c}\text { Input } \\
\text { capacitance }\end{array}$ & 200nF / $400 \mathrm{~V}$ MKP EPCOS \\
\hline $\begin{array}{c}\text { Ou1put } \\
\text { capacitance }\end{array}$ & $\begin{array}{c}1 \mu \mathrm{F} / 400 \mathrm{~V} \text { MKP EPCOS } \\
1000 \mu \mathrm{F} / 50 \mathrm{~V} \text { electrolytic PANASONIC }\end{array}$ \\
\hline $\begin{array}{l}\text { Coupled } \\
\text { inductor }\end{array}$ & $\begin{array}{r}\text { E20/10/5 3F3 Lm }=600 \mu \mathrm{H} \text { n }=0.44 \text { FERROXCUBE (US) } \\
\text { E20/10/5 3F3 Lm }=3 \mathrm{mH} \text { n }=0.2 \text { FERROXCUBE (EU) }\end{array}$ \\
\hline Input rectifier & $4 \times 1 \mathrm{~N} 40011000 \mathrm{~V} / 1 \mathrm{~A}$ DIODES \\
\hline Power MOSFET & STP10NM65N 650V/9A STMicroelectronics \\
\hline Power diode & STTH803D 8A / 300V STMicroelectronics \\
\hline LED string & 7 x LXK2PW14T00 HB-LEDs LUXEON \\
\hline Control IC & NCL30000 ON Semiconductors \\
\hline
\end{tabular}

The prototype was tested until both the prototype temperature and HB-LED temperature stabilized at the aforementioned specifications. The final operating temperature was reached after 75 min of operation. Figure 19 shows the line current waveforms of the prototype. As can be seen, these waveforms are highly sinusoidal. Figure 20 shows the evolution of the PF, THD and efficiency versus the line input voltage. As can be seen, the prototype complies with ENERGY STAR ${ }^{\circ}$ regulations, its THD is very low and its efficiency is also higher than traditional solutions for retrofit lamp applications even when using dissipative snubbers.

\section{b) EU HB-LED driver design}

The rated operating conditions of the second prototype are: $\mathrm{V}_{\mathrm{gp}} / \sqrt{2}=190-265 \mathrm{~V}, \mathrm{~V}_{\mathrm{o}}=22.5 \mathrm{~V}$ (i.e., $\mathrm{M}=22.5 / 230 \sqrt{2}=0.07$ ), $\mathrm{I}_{\mathrm{o}}=0.5 \mathrm{~A}$ and $\mathrm{P}_{\mathrm{g}}=12.5 \mathrm{~W}$. In this case, the coupled inductor was also designed as specified in Section III.B (i.e., $\mathrm{n}=0.2$ and $\mathrm{L}_{\mathrm{m}}=3$ 


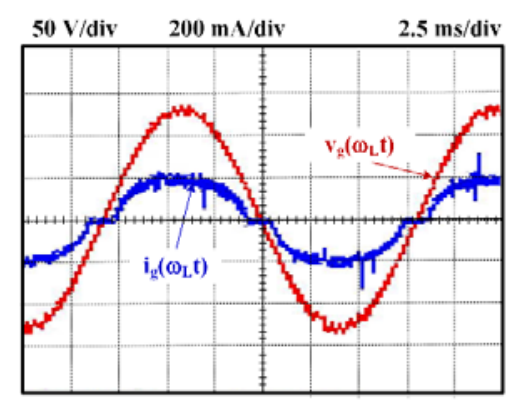

(a)

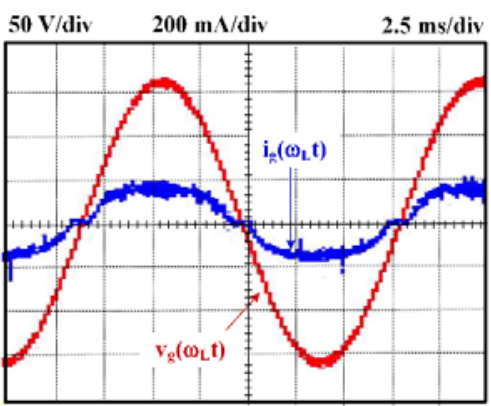

(b)

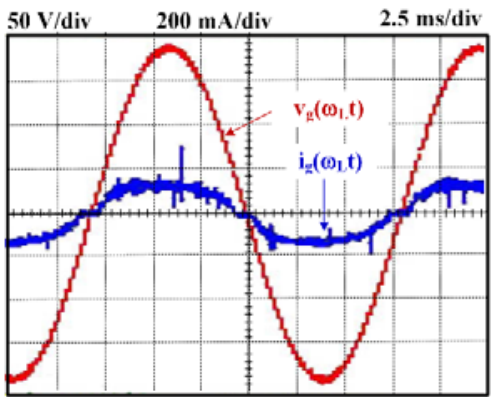

(c)

Figure 19. Line current of the US prototype for different input voltages: a) 90 Vrms. b) 110 Vrms. c) 130 Vrms.

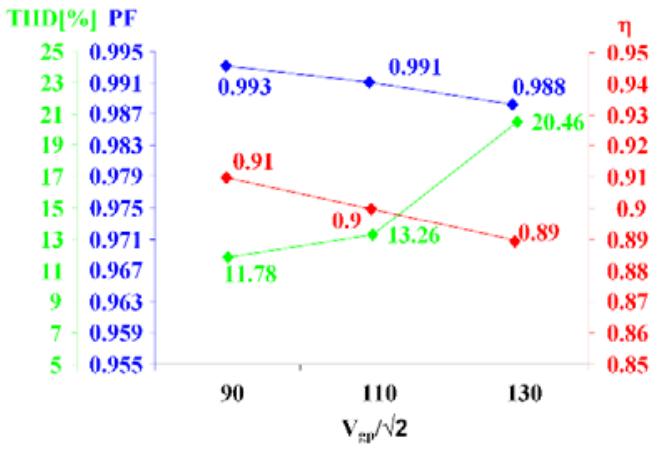

Figure 20. Evolution of the PF, THD and efficiency versus the line input voltage.
$\mathrm{mH})$. This design introduces the following variation in the switching frequency: $f_{\text {Smin }}=60 \mathrm{kHz}$ and $f_{\text {Smax }}=200 \mathrm{kHz}$.

The prototype was likewise tested until both the prototype temperature and HB-LED temperature stabilized at the aforementioned specifications. The final operating temperature was reached after $70 \mathrm{~min}$ of operation. Figure 21 shows the line current waveforms of the prototype. As can be seen, these waveforms are also highly sinusoidal. The evolution of the PF,

THD and efficiency versus the line input voltage are shown in Fig. 22. In this case, the efficiency is lower than that of the US prototype; however, it is higher than traditional solutions for retrofit lamp applications even when using dissipative snubbers in this prototype. Finally, Fig. 23 shows the experimental compliance with EN 61000-3-2 Class D regulations. This compliance was expected due to the fact that $\mathrm{M}=0.07$ is lower than 0.84 (Fig. 16).

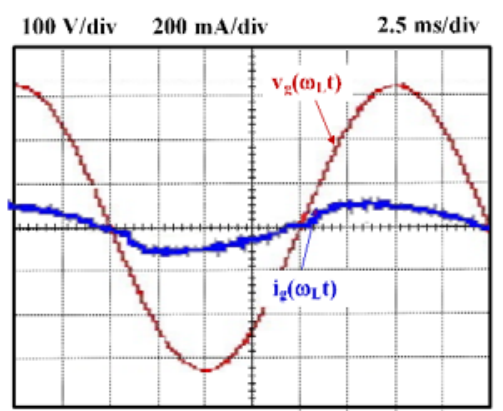

(a)

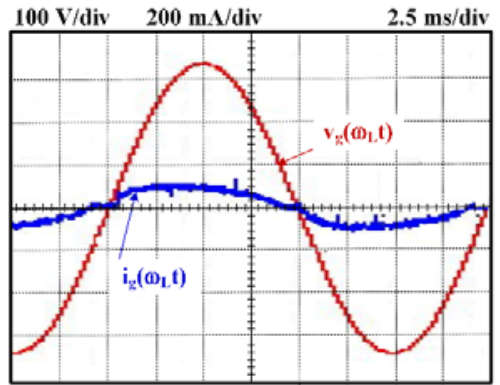

(c)

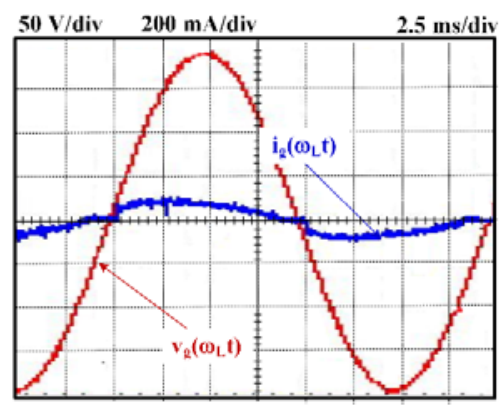

(b)

Figure 21. Line current of the EU prototype for different input voltages: a) $190 \mathrm{Vrms}$. b) $230 \mathrm{Vrms}$. c) $265 \mathrm{Vrms}$. 


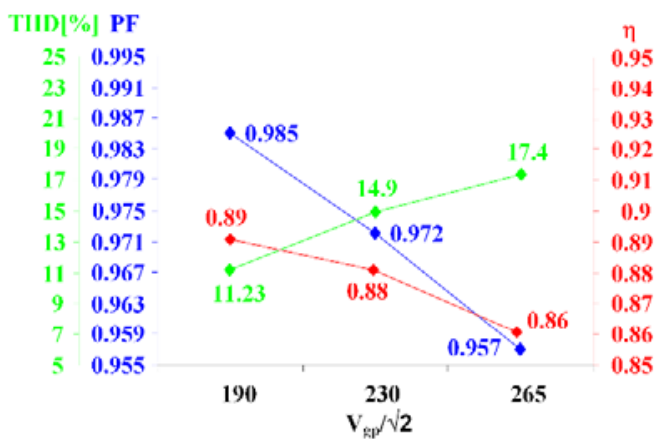

Figure 22. Evolution of the PF, THD and efficiency versus the line input voltage.

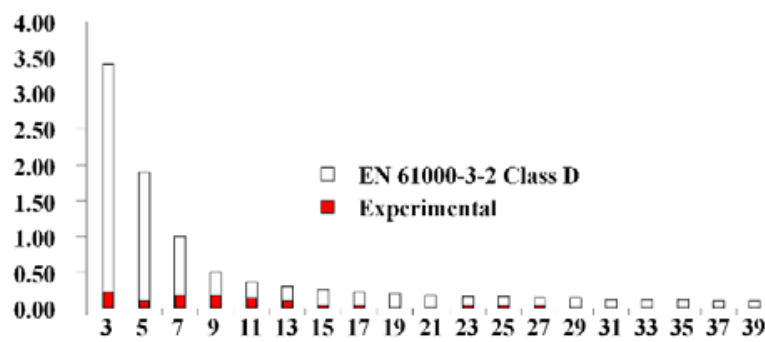

Figure 23. Harmonic content of the input current versus Class D limits.

\section{CONCLUSIONS}

This paper presents a low-cost, high efficiency and highvoltage high-step-down ratio between input and output voltage topology based on a very simple concept: the use of a Loss-Free Resistor (LFR) connected in series with the rectified mains to shape the line input current. The analysis carried out shows that if a flyback converter operating in Boundary Conduction Mode (BCM) is used as a LFR connected in series with rectified mains, the proposed solution can increase efficiency with respect to traditional solutions for retrofit lamp applications based on flyback converter placed in parallel with mains In this case we sacrifice sinusoidal input current. However, the input current distortion introduced is very slight, and the compliance with international regulations is assured. The number, rating and size of the components of the proposed solution is the same as driving circuits based on simple flyback converter, putting special attention in bulky components as the coupled inductor and output capacitor. As basic flyback solutions, the proposed topology cannot eliminate the electrolytic output capacitor. Nevertheless, this is the price to pay for a very low-cost solution. The main drawback of the proposed solution is the variable switching frequency needed in order to obtain both high efficiency and high PF.

Finally, a US and a European $12 \mathrm{~W}$ experimental prototype were respectively developed to validate the theoretical results. The experimental results show that the proposed ac-dc HB-LED driver is an efficient solution. The proposed solution thus seems to be an attractive option in the case of ac-dc High-Brightness Light-
Emitting Diode (HB-LED) drivers for replacing incandescent bulb lamps.

\section{REFERENCES}

[1] Azevedo, I.L.; Morgan, M.G.; Morgan, F, "The Transition to Solid-State Lighting," Proceedings of the IEEE, vol.97, no.3, pp.481-510, March 2009.

[2] Shur, M.S.; Zukauskas, R. "Solid-State Lighting: Toward Superior Illumination," Proceedings of the IEEE, vol.93, no.10, pp.1691-1703, Oct. 2005.

[3] [3] H.-J. Chiu, Y.-K. Lo, J.-T. Chen, S.-J. Cheng, C.-Y. Lin, S.-C. Mou, "A High-Efficiency Dimmable LED Driver for Low-Power Lighting Application" IEEE Trans. on Industrial Electronics, vol. 57, no. 2, pp. 735-743, Feb 2010.

[4] Yan-Cun Li; Chern-Lin Chen;, "A Novel Single-Stage High-PowerFactor AC-to-DC LED Driving Circuit With Leakage Inductance Energy Recycling," Industrial Electronics, IEEE Transactions on , vol.59, no.2, pp.793-802, Feb. 2012.

[5] Lamar, D.G.; Arias, M.; Rodriguez, A.; Fernandez, A.; Hernando, M.M.; Sebastian, J., "Design-Oriented Analysis and Performance Evaluation of a Low-Cost High-Brightness LED Driver Based on Flyback Power Factor Corrector," Industrial Electronics, IEEE Transactions on , vol.60, no.7, pp.2614,2626, July 2013.

[6] Yan-Cun Li; Chern-Lin Chen, "A Novel Primary-Side Regulation Scheme for Single-Stage High-Power-Factor AC-DC LED Driving Circuit," Industrial Electronics, IEEE Transactions on , vol.60, no.11, pp.4978,4986, Nov. 2013

[7] Electromagnetic compatibility (EMC)-part 3: Limits-section 2: Limits for harmonic current emissions (equipment input current $<16 \mathrm{~A}$ per phase), IEC1000-3-2 Document, 1995.

[8] Draft of the proposed CLC Common Modification to IEC 61000-3-2 Document, 2006.

[9] Draft of the proposed CLC Common Modification to IEC 61000-3-2/A2 Document, 2010.

[10] Revised ENERGY STAR Program Requirements for Solid-State Lighting Luminaires: Eligibility Criteria - Version 1.1, December 2008.

[11] Singer, S.; "Realization of loss-free resistive elements," Circuits and Systems, IEEE Transactions on , vol.37, no.1, pp.54-60, Jan 1990.

[12] Singer, S.; Erickson, R.W.; "Canonical modeling of power processing circuits based on the POPI concept," Power Electronics, IEEE Transactions on, vol.7, no.1, pp.37-43, Jan 1992.

[13] Singer, S.; Erickson, R.W.; "Power-source element and its properties", Circuits, Devices and Systems, IEE Proceedings - , vol.141, no.3, pp.220-226, Jun 1994.

[14] Madigan, M.T.; Erickson, R.W.; Ismail, E.H., "Integrated high-quality rectifier-regulators," Industrial Electronics, IEEE Transactions on , vol.46, no.4, pp.749,758, Aug 1999.

[15] Dixon, L.H., "High Power Factor Preregulation for Off-Line Power Supplies", Unitrode Power Supply Design Seminar, 1988, p. 6.1-6.16.

[16] Garcia, O.; Cobos, J.A.; Prieto, R.; Alou, P.; Uceda, J, "Single phase power factor correction: a survey", Power Electronics, IEEE Transactions on, vol. 18, $n^{\circ} 3$, p. 749- 755, Mayo 2003.

[17] Orabi, M.; Ninomiya, T., "Nonlinear dynamics of power-factorcorrection converter," Industrial Electronics, IEEE Transactions on , vol.50, no.6, pp.1116,1125, Dec. 2003

[18] Arias, M.; Lamar, D.G.; Sebastian, J.; Balocco, D.; Diallo, A.; , "Highefficiency LED driver without electrolytic capacitor for street lighting," Applied Power Electronics Conference and Exposition (APEC), 2012 Twenty-Seventh Annual IEEE, vol., no., pp.1224-1231, 5-9 Feb. 2012.

[19] Xinke Wu; Zhaohui Wang; Junming Zhang, "Design Considerations for Dual-Output Quasi-Resonant Flyback LED Driver With CurrentSharing Transformer," Power Electronics, IEEE Transactions on vol.28, no.10, pp.4820,4830, Oct. 2013

[20] Yan, T.; Xu, J.; Zhang, F.; Sha, J.; Dong, Z., "Variable-On-TimeControlled Critical-Conduction-Mode Flyback PFC Converter," Industrial Electronics, IEEE Transactions on , vol.61, no.11, pp.6091,6099, Nov. 2014. 
[21] Yan-Cun Li; Chern-Lin Chen, "A Novel Primary-Side Regulation Scheme for Single-Stage High-Power-Factor AC-DC LED Driving Circuit," Industrial Electronics, IEEE Transactions on , vol.60, no.11, pp.4978,4986, Nov. 2013.

[22] Watson, R.; Hua, G.-C.; Lee, F.C., "Characterization of an active clamp flyback topology for power factor correction applications," Power Electronics, IEEE Transactions on , vol.11, no.1, pp.191,198, Jan 1996.

[23] Buso, S.; Spiazzi, G.; Sichirollo, F.," Study of the Asymmetrical Half Bridge Flyback Converter as an Effective Line Fed Solid State Lamp Driver" Electronics, IEEE Transactions on ,

[24] X. Qu, S.-C. Wong, and C. K. Tse, "Resonance-assisted buck converter for offline driving of power LED replacement lamps," IEEE Trans. Power Electron., vol. 26, no. 2, pp. 532-540, Feb. 2011.

[25] Sebastian, J.; Fernandez, A.; Villegas, P.J.; Hernando, M.M.; Lopera J.M.; , "Improved active input current shapers for converters with symmetrically driven transformer," Industry Applications, IEEE Transactions on, vol.37, no.2, pp.592-600, Mar/Apr 2001.
[26] Fernandez, A.; Sebastian, J.; Villegas, P.J.; Hernando, M.M.; Alvarez Barcia, L., "Low-power flyback converter with synchronous rectification for a system with AC power distribution," Industrial Electronics, IEEE Transactions on, vol.49, no.3, pp.598,606, Jun 2002.

[27] Villarejo, J.A.; Sebastian, J.; Soto, F.; De Jodar, E., "Optimizing the Design of Single-Stage Power-Factor Correctors," Industrial Electronics, IEEE Transactions on , vol.54, no.3, pp.1472,1482, June 2007.

[28] T. Jiun-Ren, W. Tsai-Fu, W. Chang-Yu, C. Yaow-Ming, and L. MingChuan, "Interleaving Phase Shifters for Critical-Mode Boost PFC," Power Electronics, IEEE Transactions on, vol. 23, pp. 1348-1357, 2008.

[29] Y. Hu, L. Huber, and M. Jovanovic, "Single-Stage, Universal-Input AC/DC LED Driver with Current-Controlled Variable PFC Boost Inductor," Power Electronics, IEEE Transactions on, vol. PP, pp. 1-1, 2010.

[30] M.Arias, M; Lamar, D. G.; Linera, F. F.; Balocco, D.; Aguissa Diallo, A.; Sebastián, J.; , "Design of a Soft-Switching Asymmetrical HalfBridge Converter as Second Stage of an LED Driver for Street Lighting Application," Power Electronics, IEEE Transactions on , vol.27, no.3, pp.1608-1621, March 2012. 